\title{
Management of leprosy on the basis of the epidemiology of disabilities
}

\author{
R. GANAPATI, C. R. REVANKAR \& S. KINGSLEY \\ Bombay Leprosy Project, Vidnyan Bhavan, 11 VN Purav Marg \\ Sion-Chunabhatti, Bombay 400 022/India
}

\section{Accepted for publication 7 November 1995}

\begin{abstract}
Summary With the reduction on caseload due to the impact of multidrug therapy (MDT) in most parts of India, we believe that there is a need to understand the epidemiology of disabilities in leprosy which may not necessarily correlate with the distribution pattern of active disease. We present a methodology of data collection and verification taking the district as a unit to calculate the prevalence rate of disability as an exclusive entity in the district population, unrelated to the problems posed by the communicable component of leprosy. This study indicated that the prevalence rate of Grade II disabilities in 14 hyperendemic districts was $0 \cdot 82 / 1000$, whereas it was $0 \cdot 22 / 1000$ in low endemic districts. Limb disability data collected from three hyperendemic districts in Andhra Pradesh following task-oriented training enabled the paramedical worker to offer services to 5753 disabled patients after assessing the disability caseload per worker.
\end{abstract}

\section{Introduction}

The distribution pattern of disabilities in leprosy may not necessarily correlate with the disease distribution as a whole. For instituting an ideal field-based management programme exclusively for disabilities, a special strategy is called for. Multidrug therapy (MDT) has created a definite impact in reducing the 'caseload' represented by a declining active disease prevalence, as well as a declining 'disability rate' among new cases. However, the pool of disabilities among old monotherapy-cured cases, new cases detected with disabilities and relatively lesser numbers of cases developing disabilities during MDT and the surveillance period is left over as a post-MDT residual problem. We believe that unless we study the epidemiology of disability as an exclusive entity, unrelated to the problems posed by the communicable component of leprosy, we cannot do full justice to the management of leprosy as a whole. In this study we have taken the district as the unit for assessment of the prevalence rate of disabilities before launching a field-based disability care programme. 


\section{Material and methods}

In order to understand the epidemiology of disabilities at the district level, we made an attempt to collect data from:

hyperendemic MDT districts of the National Leprosy Eradication Programme (NLEP) in India supported by the Swedish International Development Authority (SIDA) using questionnaires during the recent evaluation (Table 1);

low endemic MDT districts in Gujarat through routinely available data in collaboration with the CIBA supported 'Comprehensive Leprosy Care Project' (Table 2); and

hyperendemic MDT district in Andhra Pradesh supported by the Norwegian International Development Authority (NORAD) through a specially designed survey proforma (see Appendix 1) in collaboration with the State Directorate of Health Services (Leprosy) (Table 3).

\section{Results}

These data have been collected from the available records since the establishment of leprosy control units till the end of December 1993. Therefore the period may not be even and comparable.

Tables 1 and 2 indicate the magnitude of the problem in relation to the population in hyperendemic districts and relatively less in low endemic districts. The data, however, do not suggest at field level the services that should be provided according to the needs of the patients. We, therefore, developed a new method of collecting data using a simple proforma (see Appendix) in two endemic districts in Andhra Pradesh during the operation of a special project on 'Early Rehabilitation and Disability Care Programme' supported by NORAD.

Table 1. Prevalence of leprosy disability in hyperendemic districts

\begin{tabular}{rlrcrcr}
\hline Sr No & \multicolumn{1}{c}{ District } & $\begin{array}{c}\text { Population } \\
(1991 \text { census) }\end{array}$ & $\begin{array}{c}\text { Registered cases* } \\
\text { (old + new) }\end{array}$ & $\begin{array}{c}\text { Disabled cases } \dagger \\
\text { (old + new) }\end{array}$ & $\begin{array}{c}\text { Disability } \\
\%\end{array}$ & $\begin{array}{c}\text { Disability } \\
\text { PR/1000 }\end{array}$ \\
\hline 1 & Krishna & 3693179 & 54367 & 2616 & $4 \cdot 81$ & $0 \cdot 71$ \\
2 & Srikakulam & 2321126 & 59703 & 1182 & $1 \cdot 97$ & $0 \cdot 50$ \\
3 & Vishakapat nam & 3272110 & 40032 & 1055 & $2 \cdot 63$ & $0 \cdot 32$ \\
4 & Deogarh & 918233 & 19380 & 3021 & $15 \cdot 58$ & $3 \cdot 29$ \\
5 & Baroda & 3094692 & 28125 & 2287 & $8 \cdot 13$ & $0 \cdot 72$ \\
6 & Belgaum & 3593606 & 26061 & 1720 & $6 \cdot 59$ & $0 \cdot 48$ \\
7 & Dharwar & 3503150 & 32236 & 1752 & $5 \cdot 43$ & $0 \cdot 50$ \\
8 & Amaravati & 2008568 & 41627 & 78 & $0 \cdot 18$ & $0 \cdot 04$ \\
9 & Wardha & 1065589 & 41490 & 1173 & $2 \cdot 82$ & $1 \cdot 19$ \\
10 & Chandrapur & 1768958 & 48981 & 320 & $0 \cdot 65$ & $0 \cdot 18$ \\
11 & Tanjavur & 4526701 & 63741 & 5702 & $8 \cdot 94$ & $1 \cdot 26$ \\
12 & Chengal pattu & 4620967 & 15538 & 6015 & $5 \cdot 20$ & $1 \cdot 30$ \\
13 & Purulia & 2217423 & 83997 & 3771 & $4 \cdot 48$ & $1 \cdot 70$ \\
14 & Varanasi & 4798729 & 47045 & 3041 & $6 \cdot 46$ & $0 \cdot 63$ \\
& & 41493031 & 702323 & 33833 & $4 \cdot 81$ & $0 \cdot 82$ \\
\hline
\end{tabular}

* Includes old monotherapy cases also.

†Only Grade II as per WHO disability grading (1988). 
Table 2. Prevalence of leprosy disability in low endemic districts

\begin{tabular}{llccccc}
\hline S1 No & District & $\begin{array}{c}\text { Population } \\
(1991 \text { census })\end{array}$ & $\begin{array}{c}\text { Registered cases } \\
\text { (old + new) }\end{array}$ & $\begin{array}{c}\text { Disabled cases* } \\
\text { (old + new) }\end{array}$ & $\begin{array}{c}\text { Disability } \\
\%\end{array}$ & $\begin{array}{c}\text { Disability } \\
\text { PR/1000 }\end{array}$ \\
\hline 1 & Banaskatha & 1667914 & 2501 & 186 & $7 \cdot 43$ & $0 \cdot 11$ \\
2 & Sabarkatha & 1502284 & 3059 & $781 \dagger$ & $25 \cdot 53$ & $0 \cdot 51$ \\
3 & Mehsana & 2548787 & 1614 & 359 & $22 \cdot 24$ & $0 \cdot 14$ \\
4 & Gandhinagar & 289088 & 205 & 34 & $16 \cdot 58$ & $0 \cdot 11$ \\
& & 6008073 & 7379 & 1360 & $18 \cdot 43$ & $0 \cdot 22$ \\
\hline
\end{tabular}

* Grade I and Grade II as per WHO disability grading (1988).

$\dagger$ Includes 300 disabled patients living in a leprosy home and not necessarily from the same district.

Table 3 shows the number of leprosy patients with different kinds of disabilities in relation to limbs.

The extent of the problems posed by each type of disability in relation to the population as revealed by such an analysis will be useful to plan the service delivery, because employment of paramedical workers is always based on the population in any given area.

Table 4 shows the types of services provided by paramedical staff according to needs of disabled leprosy patients after collecting data as shown in Table 3.

All the disabled patients of Prakasam and Kurnool districts were offered services through the existing leprosy staff following a task-oriented training on field deformity care. After a period of 3 years, the impact of the disability care programme could be assessed. This will form the subject of a future communication.

Table 3. Distribution of limb disabilities

\begin{tabular}{|c|c|c|c|c|c|c|c|}
\hline \multirow{3}{*}{$\frac{\text { Sl No }}{1}$} & \multirow{3}{*}{$\begin{array}{c}\text { Limb disability } \\
\text { Total disabled cases }\end{array}$} & \multicolumn{6}{|c|}{ District } \\
\hline & & \multicolumn{2}{|c|}{$\begin{array}{l}\text { Prakasam }(2750340)^{*} \\
\text { Cases: } \mathrm{PR} / 1000\end{array}$} & \multicolumn{2}{|c|}{$\begin{array}{c}\text { Kurnool }(3183624)^{*} \\
\text { Cases: PR/1000 }\end{array}$} & \multicolumn{2}{|c|}{$\begin{array}{c}\text { Cuddapah } \dagger(2259154)^{*} \\
\text { Cases: PR/1000 }\end{array}$} \\
\hline & & 1725 & 0.63 & 2310 & $0 \cdot 72$ & 1718 & $0 \cdot 76$ \\
\hline \multirow[t]{2}{*}{2} & Grade I & 415 & $0 \cdot 15$ & 864 & $0 \cdot 27$ & NA & - \\
\hline & Grade II & 1310 & $0 \cdot 48$ & 1456 & 0.46 & NA & - \\
\hline \multirow[t]{5}{*}{3} & Upper limb & & & & & & \\
\hline & Anaesthesia & 1070 & $0 \cdot 39$ & 1539 & $0 \cdot 50$ & NA & - \\
\hline & Claw hand & 923 & $0 \cdot 34$ & 1358 & 0.43 & 844 & $0 \cdot 37$ \\
\hline & Wrist drop & 30 & $0 \cdot 01$ & 40 & $0 \cdot 01$ & 23 & 0.07 \\
\hline & Finger absorption & 581 & $0 \cdot 21$ & 344 & $0 \cdot 11$ & 162 & 0.07 \\
\hline \multirow[t]{5}{*}{4} & Lower limb & & & & & & \\
\hline & Anaesthesia & 1315 & $0 \cdot 47$ & 1131 & $0 \cdot 36$ & 652 & $0 \cdot 29$ \\
\hline & $\begin{array}{l}\text { Plantar } \\
\text { Ulcer }\end{array}$ & 874 & $0 \cdot 31$ & 627 & $0 \cdot 19$ & 216 & $0 \cdot 10$ \\
\hline & Foot drop & 170 & 0.06 & 273 & $0 \cdot 20$ & 208 & 0.09 \\
\hline & Claw toes & 541 & $0 \cdot 20$ & 669 & $0 \cdot 21$ & 192 & 0.08 \\
\hline \multirow[t]{4}{*}{5} & Face/eye & & & & & & \\
\hline & Anaesthesia & 44 & $0 \cdot 02$ & 74 & 0.02 & NA & - \\
\hline & Lagophthal & 87 & $0 \cdot 03$ & 136 & $0 \cdot 04$ & 67 & 0.03 \\
\hline & Depressed nose & 139 & $0 \cdot 05$ & 162 & 0.05 & 148 & 0.07 \\
\hline
\end{tabular}

* Population as per 1991 census.

† Data provided by Dr N. Sivarama Brahmachary, District Leprosy Officer, Cuddapah, Andhra Pradesh.

NA, not available. 
Table 4. Services provided to disabled leprosy cases

\begin{tabular}{llrr}
\hline & & \multicolumn{2}{c}{ District } \\
\cline { 3 - 4 } Si No & \multicolumn{1}{c}{ Service } & Prakasam & Kurnool \\
\hline 1 & Splints & 867 & 954 \\
2 & Grip-aids & 252 & 244 \\
3 & Mini POP & 106 & 68 \\
4 & Dressing & 432 & 160 \\
5 & MCR footwear & 1315 & 514 \\
6 & Foot drop spring & 27 & Nil \\
7 & Eye care & 85 & 74 \\
8 & Care of limbs & 1360 & 1062 \\
9 & Demonstrated exercises & 614 & 728 \\
& & & \\
\hline
\end{tabular}

\section{Discussion}

The prevalence rate of disabilities is an indicator of the caseload with disabilities. A knowledge of the trends on the distribution and types of deformity is, therefore, of great value in order to establish the epidemiological and operational aspects of disability care and prevention programme which would be an integral part of leprosy control programmes. It has been observed that a uniform methodology of assessing the disabilities practised in 2 hyperendemic NORAD supported districts enabled the leprosy staff to understand the type of disability, which have resulted in providing more effective disability care in the community.

\section{Conclusion}

We believe that in order to scientifically implement a disability care programme using available field technologies, an epidemiological database at the district level is needed. To provide specific services, limb and type of disability data are required, i.e. number of claw hands, foot drops, plantar ulcers etc. It is also necessary to know the distribution of such cases at village level to workout the disability caseload per worker.

The provision of field services in low-endemic areas is likely to be more challenging considering the sparse distribution of deformity cases in the general population.

\section{Acknowledgments}

We are thankful to SIDA, New Delhi and the Deputy Director General of Health Services (Leprosy), New Delhi for permitting the collection of data from the SIDA supported MDT district during evaluation.

We are also thankful to the Director of Health Services, NLEP/WHO State Consultant and the District Leprosy Officers of NORAD-supported MDT districts of Andhra Pradesh for permitting us to implement the Deformity Care and Management Programme in Prakasam and Kurnool Districts. Thanks are also due to NORAD for their generous financial support to implement the abovementioned project. 
The secretarial assistance provided by $\mathrm{Mr} \mathrm{K}$. Sreedharan in preparing this article is acknowledged.

\section{References}

${ }^{1}$ WHO Expert Committee on Leprosy, Sixth Report WHO Technical Report Series, No. 786, WHO Geneva 1988.

\section{Appendix}

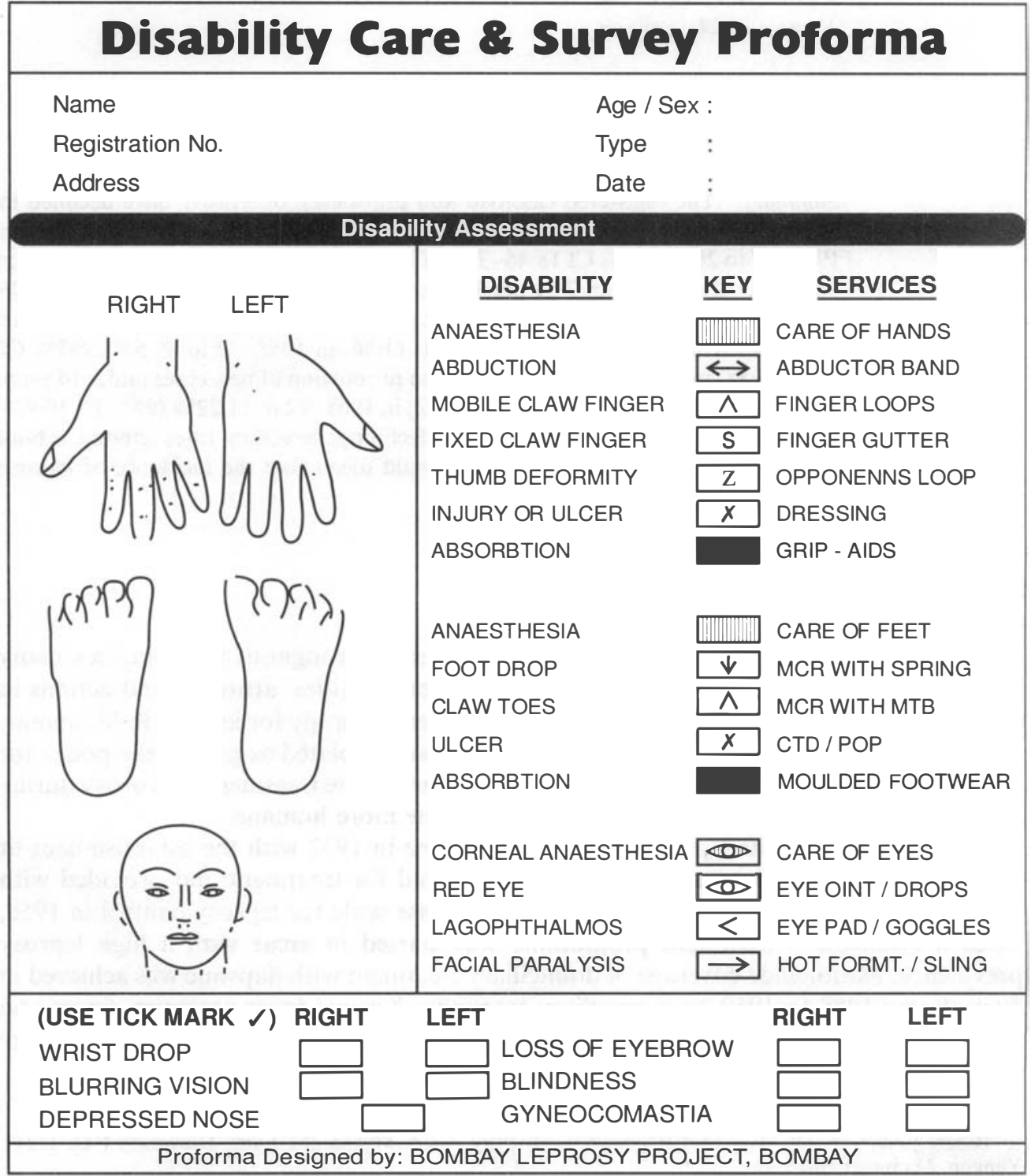

